2006 ERSD Annual Report

DOE-BER Environmental Remediation Sciences Project \#1024942

\title{
Mechanisms and Dynamics of Abiotic and Biotic Interactions at Environmental Interfaces
}

\section{The PNNL component of the Stanford Environmental Molecular Sciences Institute (EMSI): "Chemical and Biological Interactions at Environmental Interfaces"}

\author{
PI: Kevin M. Rosso \\ Pacific Northwest National Laboratory, Richland, WA
}

\section{Research Objectives:}

The Stanford EMSI (SEMSI) was established in 2004 through joint funding by the National Science Foundation and the OBER-ERSD. It encompasses a number of universities and national laboratories. The PNNL component of the SEMSI is funded by ERSD and is the focus of this report. This component has the objective of providing theory support to the SEMSI by bringing computational capabilities and expertise to bear on important electron transfer problems at mineral/water and mineral/microbe interfaces. PNNL staff member Dr. Kevin Rosso, who is also 'matrixed' into the Environmental Molecular Sciences Laboratory (EMSL) at PNNL, is a co-PI on the SEMSI project and the PNNL lead. The EMSL computational facilities being applied to the SEMSI project include the 11.8 teraflop massively-parallel supercomputer. Science goals of this EMSL/SEMSI partnership include advancing our understanding of: $i$ ) The kinetics of $\mathrm{U}(\mathrm{VI})$ and $\mathrm{Cr}(\mathrm{VI})$ reduction by aqueous and solid-phase Fe(II), ii) The structure of mineral surfaces in equilibrium with solution, and iii) Mechanisms of bacterial electron transfer to iron oxide surfaces via outer-membrane cytochromes.

\section{Research Progress and Implications:}

As of the end of FY06, the PNNL-component of this two-year old project has a number of accomplishments and publications to report towards achieving our stated science goals, as exemplified below. Furthermore, as described below, this component has yielded increased utilization and visibility of the EMSL through new collaborations and graduate students traveling to and conducting research at the EMSL for extended periods of time.

Uranium is a pollutant of substantial importance to the ERSD. Uranium mobility is directly tied to its oxidation state and therefore the kinetics of interconversion between these oxidation states is relevant. While $\mathrm{U}(\mathrm{VI})$ in the form of the uranyl cation is readily reduced by a range of natural reductants, in contrast complexation of uranyl by carbonate greatly reduces its reduction potential and imposes increased electron transfer (ET) distances. Given that carbonate is a common environmental ligand, this works against our ability to reductively immobilize uranium in subsurface environments. Very little is known about the molecular-scale processes 
involved in uranium reduction from $\mathrm{U}(\mathrm{VI})$ to $\mathrm{U}(\mathrm{V})$ to $\mathrm{U}(\mathrm{IV})$. The objective of this research topic was to determine the molecular-level reduction mechanisms and efficacy of reduction of uranium-carbonate complexes by aqueous $\mathrm{Fe}(\mathrm{II})$.

Through collaboration with Dr. Martin Schoonen (Stony Brook) and his graduate student Mathew Wander, in conjunction with computing resources made available at the EMSL for the SEMSI project, we examined the theoretical kinetics of ET from ferrous iron to triscarbonato uranyl in aqueous solution. Given the well-known ability of $\mathrm{Ca}^{2+}$ to bind to triscarbonato uranyl, we hypothesized that $\mathrm{Fe}^{2+}$ could do the same. A combination of molecular dynamics (MD) simulations and density functional theory (DFT) electronic structure calculations were employed first to compute the probability of forming the charge-neutral ternary $\mathrm{Fe}_{2} \mathrm{UO}_{2}\left(\mathrm{CO}_{3}\right)_{3}\left(\mathrm{H}_{2} \mathrm{O}\right)_{8}$ complex in solution. We then proceeded to compute the parameters that enter into Marcus' ET theory, including the thermodynamic driving forces, reorganization energies, and electronic coupling matrix elements. MD simulations predicted that two ferrous iron atoms will strongly bind in an inner-sphere fashion to the three-membered carbonate ring of triscarbonato uranyl (Fig. 1). Through a sequential proton-coupled electron transfer mechanism (PCET), the first ET step converting $\mathrm{U}(\mathrm{VI})$ to $\mathrm{U}(\mathrm{V})$ is predicted by DFT to occur with an energy barrier that corresponds to a rate on the order of $\sim 1 \mathrm{~s}^{-1}$ (Fig. 1). The second ET step converting $U(V)$ to $\mathrm{U}(\mathrm{IV})$ is predicted to be significantly endergonic. Therefore, $\mathrm{U}(\mathrm{V})$ is a stabilized end-product in this ET system, not U(IV). The implications are that only partial uranium reduction can be expected in solutions bearing both Fe(II) and carbonate even though they can form a strong ternary complex, and the reduction will proceed extremely slowly. This work involved more than three months of residence time at the EMSL for Mathew Wander under the direction of Dr. Kevin Rosso, resulting in a publication listed below.

Another research goal is to understand rates of $\mathrm{U}(\mathrm{VI})$ reduction and the stability of reaction products due to reaction with $\mathrm{Fe}(\mathrm{II})$-bearing mineral surfaces such as magnetite. Magnetite, $\left(\mathrm{Fe}^{\mathrm{II}} \mathrm{Fe}^{\mathrm{III}}{ }_{2}\right) \mathrm{O}_{4}$, forms under low oxygen conditions and is fairly common in subsurface environments. Similar to the homogeneous reduction case described above, the ability of magnetite to reduce uranium is of interest for uranium immobilization. Experimental studies have shown that reductive adsorption of $\mathrm{U}(\mathrm{VI})$ on magnetite does occur under anoxic conditions. However, the reduction is incomplete and the structure of the reaction product is poorly understood. Therefore the potential for uranium resolubilization and transport by oxidiative desorption is unknown for this system. The objective of this science topic is to determine the mechanism and kinetics of $\mathrm{U}(\mathrm{VI})$ reduction at magnetite surfaces, and to produce the first molecular-level understanding of the reduction reaction for this system. This will provide a basis for understanding the nature of the initial reaction products formed. It will also provide complementary information to ongoing experimental research using synchrotron-based crystal truncation rod methods to determine the surface structure of magnetite (100) by Dr. Tom Trainor on the SEMSI project.

This SEMSI research focused on computational determination of the availability of Fe(II) at magnetite (100) surfaces and the rate of electron transfer between adsorbed U(VI) and lattice Fe(II) in the surface. It was performed in a collaboration with Dr. Rod Ewing and graduate student Frances Skomurski at the University of Michigan. Ms. Skomurski spent almost two months in residence at the EMSL with Dr. Rosso using the computational facilities made 
available to the SEMSI project. Two different modeling packages were used including NWChem, which is a suite of molecular modeling routines that was created by the EMSL.

We used quantum mechanical periodic calculations to determine the charge ordering of $\mathrm{Fe}^{\mathrm{II}} / \mathrm{Fe}^{\mathrm{III}}$ in the octahedral sub-lattice of bulk magnetite, as well as at vacuum-terminated and hydrated magnetite (100) surfaces. On this sub-lattice, $\mathrm{Fe}^{\mathrm{II}}$ and $\mathrm{Fe}^{\mathrm{III}}$ atoms exist in equal numbers, and electron hopping occurs between these atoms above the Verwey temperature of $120 \mathrm{~K}$. Our calculations at $0 \mathrm{~K}$ predict that $\mathrm{Fe}^{\mathrm{II}}$ and $\mathrm{Fe}^{\mathrm{III}}$ alternate on the octahedral sub-lattice in an orderly manner, consistent with experiment. To model the stoichiometric (100) surface of magnetite, which is polar and therefore unstable with respect to reconstruction, we adapted a reconstruction proposed in the literature to a two-dimensional periodic slab model for simultaneous geometry and charge distribution optimization. On a vacuum terminated (100) surface, an increase in the number of $\mathrm{Fe}^{\mathrm{II}}$ atoms relative to $\mathrm{Fe}^{\mathrm{III}}$ atoms occupying the surface octahedral sites was observed, most-likely due to the presence of tetrahedral $\mathrm{Fe}^{\mathrm{III}}$ atoms in the near-surface environment in this reconstruction. The increase in surface $\mathrm{Fe}^{\mathrm{II}}$ is accompanied by a decrease in $\mathrm{Fe}^{\mathrm{II}}$ in the inner-slab region. To hydrate the surface, molecular water was added above each metal Fe-atom on the surface and stable configurations were identified using MD. During quantum mechanical optimization, slab and surface atoms were allowed to relax. A decrease in the number of $\mathrm{Fe}^{\mathrm{II}}$ atoms on the slab surface is observed relative to the vacuum terminated case, and a more even distribution of $\mathrm{Fe}^{\mathrm{II}}$ is seen in inner-slab layers. In both cases, however, we observe that $\mathrm{Fe}^{\mathrm{II}}$ is available in close proximity to other $\mathrm{Fe}^{\mathrm{II}}$ atoms in surface environments, which may provide ideal 'docking' sites for reductive adsorption of uranyl.

Uranyl adsorption geometries on magnetite (100) have been evaluated by MD methods (Fig. 2) and a stable bidentate structure was identified where the uranium atom bonds to two surface $\mathrm{Fe}^{\mathrm{II}}$ atoms in its equatorial coordination plane, with remaining equatorial coordination sites occupied by water. The axial -nyl oxygen atoms lie in the plane parallel to the magnetite surface. Ab initio calculations are being performed on cluster representations of this surface complex to determine the rate of electron transfer from surface $\mathrm{Fe}^{\mathrm{II}}$ and adsorbed uranyl. The cluster calculations are currently ongoing. Ultimately the resulting ET rate will be compared to that for homogeneous reduction by $\mathrm{Fe}(\mathrm{II})$ in aqueous solution to better understand factors that control the capacity of various subsurface solid-phase and aqueous phase constituents to reductively immobilize $\mathrm{U}(\mathrm{VI})$.

\section{Planned Activities:}

FY07 activities with SEMSI investigators involving Dr. Rosso at the EMSL will include:

- Determining the kinetics of homogeneous Fe(II) oxidation by dissolved molecular oxygen through a collaboration with Drs. Cynthia Lo and Anne Chaka (NIST) and Satish Myneni (Princeton). Dr. Lo is scheduled to visit the EMSL this December, 2006.

- Modeling the kinetics of heterogeneous reduction of $\mathrm{Cr}(\mathrm{VI})$ by green rust minerals through a continuing collaboration with Dr. Martin Schoonen and Matthew Wander (Stony Brook). Mr. Wander is scheduled to return to the EMSL in February, 2007. 
- Investigating the surface structure of a new hematite morphology resulting from coupled Fe(II) oxidation and growth at hematite surfaces in collaboration with Dr. Tom Trainor (U. Alaska Fairbanks). Samples are being delivered to Dr. Trainor this December, 2006.

- Producing a theoretical model of heterogeneous $\mathrm{U}(\mathrm{VI})$ reduction kinetics by magnetite (100) surfaces in collaboration with Rod Ewing and graduate student Frances Skomurski (U. Michigan). A manuscript is under development from the two visits of Ms. Skomurski to the EMSL.

\section{Information Access:}

\section{$\underline{\text { Publications }}$}

Wander M.C.F., Kerisit S., Rosso K.M., Schoonen M.A.A. (2006) Kinetics of triscarbonato uranyl reduction by aqueous ferrous iron: A theoretical study, J. Phys. Chem. A, 110, 96919701.

Sahai N. and Rosso K.M. (2006) Computational molecular basis for improved silica surface complexation models, In Surface Complexation Modeling, Lutzenkirchen (ed.), Elsevier, 359396.

Rosso K.M. and Vaughan D.J. (2006) Sulfide mineral surfaces, Reviews in Mineralogy and Geochemistry, 61, 505-556.

Rosso K.M. and Vaughan D.J. (2006) Reactivity of sulfide mineral surfaces, Reviews in Mineralogy and Geochemistry, 61, 557-607.

Wigginton N.S., Rosso K.M., Lower B.H., Shi L., Hochella M.F., Jr. (in press) Electron tunneling properties of outer-membrane decaheme cytochromes from Shewanella oneidensis. Geochim. Cosmochim. Acta. 


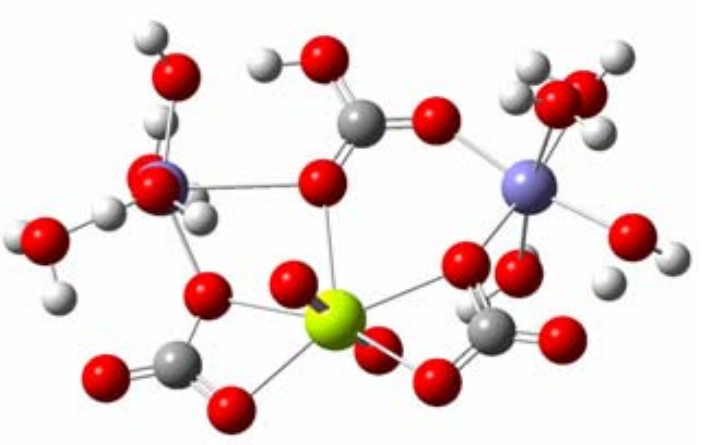

Figure 1, showing (upper left) the computed minimum energy structure for the $\mathrm{Fe}(\mathrm{II})-\mathrm{Fe}(\mathrm{II})-\mathrm{U}(\mathrm{VI})$ ternary complex with carbonate and water ligands. The yellow sphere is the uranium atom, red spheres are oxygen atoms, blue spheres are iron atoms, grey spheres are carbon atoms, and white spheres are hydrogen atoms, (upper right) the potential of mean force computed for the formation of the complex, and (right) Calculated potential energy surfaces for the sequential proton-coupled electron transfer pathways. The barrier equates to a $\mathrm{U}(\mathrm{VI})$ reduction rate of $1 \mathrm{~s}^{-1}$.
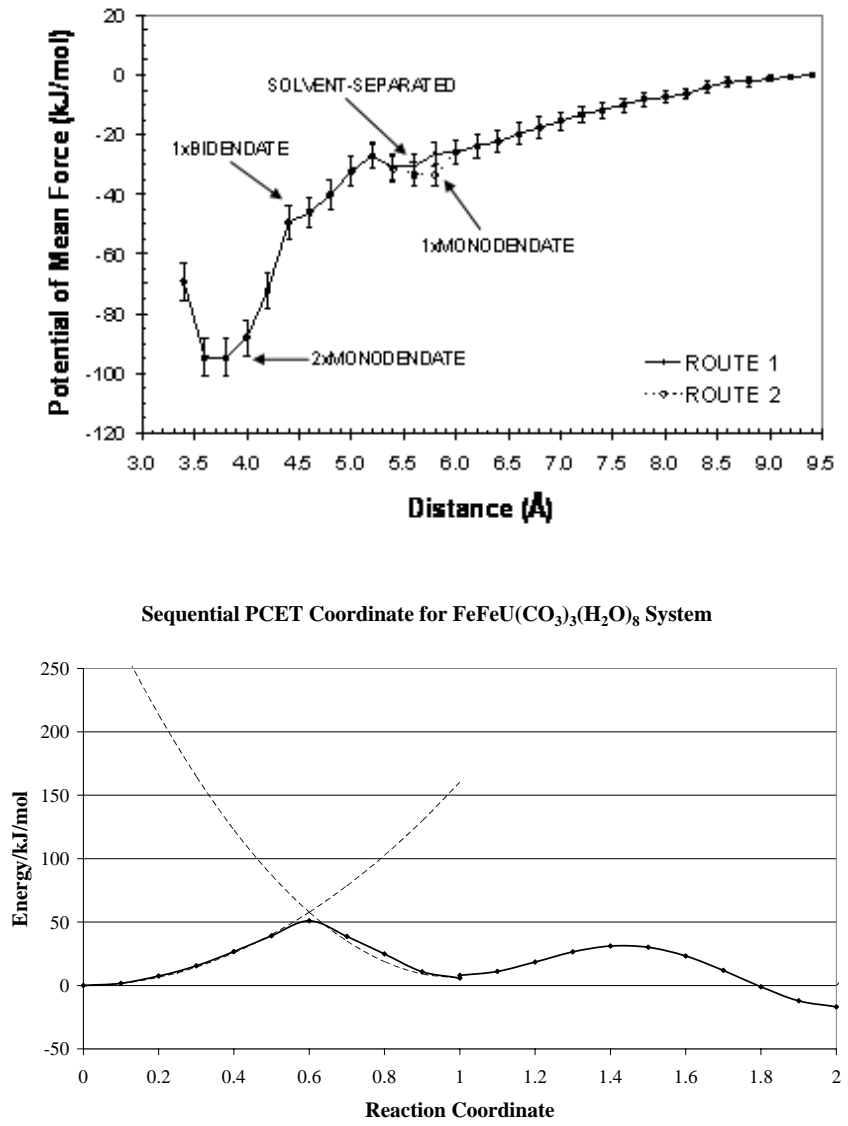

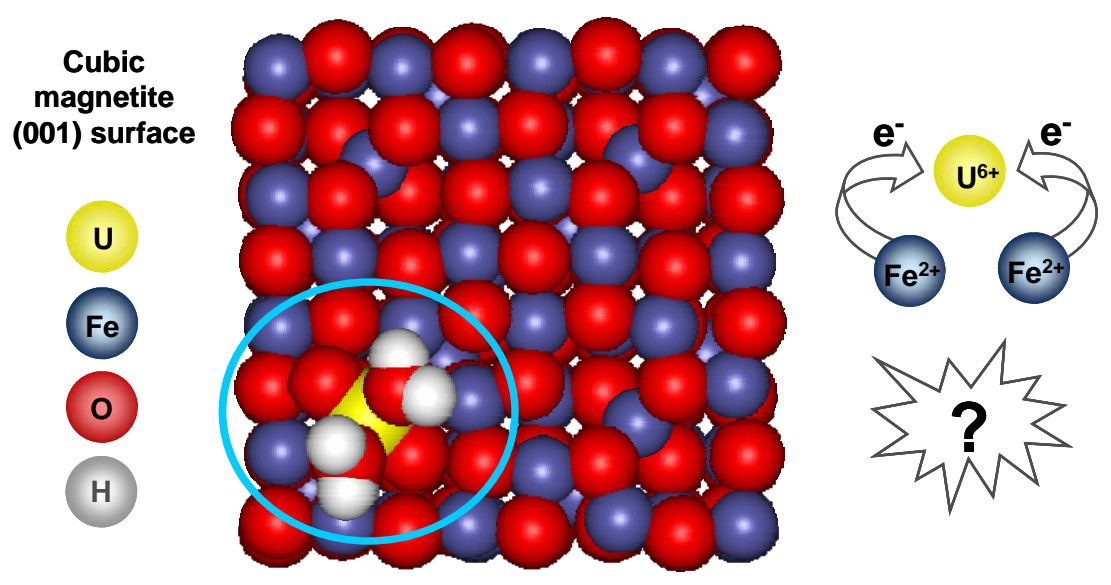

Figure 2. A hypothetical hydrated uranyl surface complex on magnetite (100) with solvent water not shown for clarity. The structure of this surface complex, and the rate of U(VI) reduction by $\mathrm{Fe}(\mathrm{II})$ in the magnetite near-surface are being determined using a combination of MD simulations and electronic structure calculations being performed at the EMSL. 